This document is the accepted manuscript version of the following article: Haller, C. M., Buerzle, W., Brubaker, C. E., Messersmith, P. B., Mazza, E., Ochsenbein-Koelble, N., ... Ehrbar, M. (2011). Musse1-mimetic tissue adhesive for fetal membrane repair: a standardized ex vivo evaluation using elastomeric membranes. Prenata1 Diagnosis, 31(7), 654-660.

https://doi.org/10.1002/pd.2712

\title{
Mussel-mimetic tissue adhesive for fetal membrane repair: a standardized ex vivo
}

\section{evaluation using elastomeric membranes}

C.M. Haller, $\mathrm{MSc}_{1,4}$, W. Buerzle, $\mathrm{MSc}_{2}$, C.E. Brubaker, $\mathrm{PhD}_{3}$, P.B. Messersmith, $\mathrm{PhD}_{3}$, E. Mazza, $\mathrm{PhD}_{2,5}$,

N. Ochsenbein-Koelble ${ }_{1}, \mathrm{MD}, \mathrm{R}$. Zimmermann, $\mathrm{MD}_{1}$, M. Ehrbar, $\mathrm{PhD}_{1,4}$ *

Running title: Mussel glue for fetal membrane repair

1 Department of Obstetrics, University Hospital Zurich, Switzerland

2 Department of Mechanical Engineering, Swiss Federal Institute of Technology,

Zurich, Switzerland

з Biomedical Engineering Department, Northwestern University, Evanston, Illinois,

USA

4 Zurich Centre for Integrative Human Physiology, Switzerland

5 EMPA, Materials Science and Technology, Dübendorf, Switzerland

*Corresponding Author: M. Ehrbar, Department of Obstetrics, Nord 1, C-120, Frauenklinikstr. 10, University Hospital, Zurich, E-mail: martin.ehrbar@,usz.ch, Tel: +41 (0)44 25585 13, Fax: +41 (0)442554430.

Keywords: Fetal membrane repair; iatrogenic PPROM; membrane sealing; mussel glue sealant 


\section{Abstract}

\section{Objective}

Iatrogenic preterm premature rupture of membranes (iPPROM), the main complication of invasive interventions in the prenatal period, seriously limits the benefit of diagnostic or surgical prenatal procedures. This study aimed to evaluate preventive plugging of punctured fetal membranes in an ex vivo situation using a new mussel-mimetic tissue adhesive (mussel glue) to inhibit leakage.

\section{Methods}

A novel biomechanical test device that tests the closure of injured membranes under nearphysiological conditions was used. Mussel glue, a poly(ethylene glycol)-based hydrogel, was used to seal membrane defects of up to $3 \mathrm{~mm}$ in mechanically well-defined elastomeric membranes with three different degrees of stiffness.

\section{Results}

Elastomeric test membranes were successfully employed for testing mussel glue under welldefined conditions. Mussel glue plugs were distended by up to $94 \%$, which translated to an improved sealing efficiency on elastomeric membranes with high stiffness. For the stiffest membrane tested, a critical burst pressure of $48 \mathrm{mbar}(36 \mathrm{mmHg})$ was accomplished in this ex vivo setting.

\section{Conclusions}

Mussel glue appears to efficiently seal membrane defects under well standardized ex vivo conditions. As repaired membranes resist pressures measured in amniotic cavities, mussel glue might represent a novel sealing method for iatrogenic membrane defects. 


\section{Introduction}

With increasing numbers of invasive interventions in the prenatal period for diagnostic or therapeutic purposes, the iatrogenic preterm pre-labor rupture of fetal membranes (iPPROM) becomes more and more important. The healing potential of fetal membranes is very limited, or even absent, as shown by a histological follow-up study. In fact, several months after the intervention, fetoscopic puncture sites had similar extension and showed no obvious signs of healing. Rather, spontaneous closure of needle punctures may be attributed to the relative sliding of the amnion and chorion against one another. This could also be due to the remaining attachment of the chorion to the decidual layer at the uterine wall by means of fibrin or any other crust associated with a healing process (Gratacos et al., 2006).

In monochorionic twin pregnancies, prenatal interventions like the selective laser coagulation of placental anastomoses are widely-accepted treatments for twin-to-twin transfusion syndrome (TTTS) (Senat et al., 2004). Further developments in prenatal invasive procedures provide promising therapeutic options for other fetal diseases, such as congenital diaphragmatic hernia $(\mathrm{CDH})$, by placing a balloon into the fetal trachea at 26 weeks of gestation with fetoscopic removal at 34 weeks (Jani et al., 2009). However, such potentially beneficial interventions might be seriously limited by the relatively high occurrence of iPPROM after fetoscopic intervention, ranging between 4\% and 100\% (Deprest et al., 2010). Severe complications resulting from premature birth include respiratory distress syndrome (RDS), cerebral palsy, blindness, deafness, kernicterus, or necrotizing enterocolitis.

Today, treatment options to restore fetal membrane integrity are very limited; further, none have made it into clinical practice. Several strategies to repair fetal membranes, such as plugging, biological healing, or sealing by surgical glues, were evaluated (Devlieger et al., 2006). Attempts to seal the fetoscopic entry site by collagen scaffolds might be limited by the stability of the matrix, resulting in a lack of long-term stability. Based on the hypothesis that 
cell instructive scaffolds can induce a biological repair, decellularized amnion tissue was evaluated in a rabbit gestational model (Mallik et al., 2007, Ochsenbein-Kolble et al., 2007). Although some endogenous cells were recruited to the matrix plug during the postoperative phase of the experiment, the sealing of the fetal membrane mainly relied on closure of the puncture site by the plug (Mallik et al., 2007, Ochsenbein-Kolble et al., 2007). The limited healing capacity of fetal membranes and the instability of plugging materials might limit the practicality of these approaches. Tissue adhesives that exhibit efficient, non-disruptive, and non-toxic bonding to fetal membranes under wet gluing conditions might be a more viable alternative.

The group of Phillip Messersmith has described the formation of a hydrogel glue by conferring an ability of marine blue mussels to firmly adhere to a wide variety of materials upon poly(ethylene glycol) (PEG) (Lee et al., 2002, Lee et al., 2007). This mussel mimetic tissue adhesive (mussel glue) is based on branched PEG, which is functionalized with the rare amino acid residue 3,4 dihydroxyphenylalanine (DOPA) present in high concentrations in mussel foot proteins (Lee et al., 2002, Lee et al., 2007, Waite, 1999, Waite and Tanzer, 1980). By conversion of DOPA under oxidative conditions, highly reactive DOPA-quinone is formed, allowing native mussel adhesive protein adhesion to take place in a wet, normal saline environment. A PEG polymer containing a DOPA analogue in the form of a reactive catechol group (cPEG) (Brubaker et al., 2010, Burke et al., 2007, Lee et al., 2002, Messersmith, 2008, Yamada et al., 2000) has not shown any signs of cytotoxicity in vitro (Bilic et al., 2010) and has also been successfully employed in in vivo studies (Brubaker et al., 2010). Therefore, mussel glue seems to be a potential candidate for sealing fetal membrane defects and preventing amniotic fluid leakage.

Thus, the aim of the present study was to develop a standardized regimen to test the properties of mussel glue for the sealing of fetal membranes. We developed an experimental setup that 
allows for the loading of membranes in a multi-axial stress state through the application of a fluid pressure on one side of a circular membrane test piece. This setup generates loading conditions that are more physiologically representative compared to the well known ball-burst tester, a setup that induced a localized equi-biaxial stress field through a spherical indenter punching the membrane (El Khwad et al., 2005). As the physical and biological properties of chorioamniotic membranes are highly variable, characterization of the mechanical performance of sealing materials might be largely hindered by non-homogenous samples. Therefore, elastomeric membranes were used as model for the experimental evaluation of the mussel-mimetic adhesive and its repair capabilities. The elastomeric membranes consist of the acrylic elastomer VHB 4910, which is characterized by high extensibility and a pronounced time dependence of its mechanical response. VHB 4910 has been recently employed for the realization of electro-active polymer actuators, also called "artificial muscles" (Bar-Cohen, 2004). Here, in a series of elastomeric membranes with three different mechanical degrees of stiffness, defects were created and glued with mussel glue under standardized conditions.

\section{Materials and Methods}

\subsection{Mussel mimetic sealant}

The production and characterization of mussel glue, a catechol-functionalized poly(ethylene glycol) (cPEG) lacking the primary amine of the DOPA amino acid, was performed as described elsewhere (Brubaker et al., 2010). For the formation of hydrogels, equal volumes of cPEG precursor solution $(300 \mathrm{mg} / \mathrm{mL}$ in phosphate-buffered saline (PBS) and $0.01 \% \mathrm{wt}$ Brilliant Blue (Shanghai Chemorole Ltd)) and sodium periodate solution (12 mg/mL in water) were mixed by pipetting. Sodium periodate initiated gelation, which was achieved when reactive dopamine groups formed covalent cross-links (Lee et al., 2002). This was allowed to proceed for five minutes at room temperature. 


\subsection{Design and setup of the loading device}

A custom-built device to mechanically stretch membranes in a biaxial way was used. The device consisted of an aluminum cylinder with a $50 \mathrm{~mm}$ inner diameter that was mounted by clamping membrane samples between the cylinder and a cover ring (Figure 1). The cylinder was connected to both inlet and outlet tubing. The membranous tissue was inflated on the water-filled cylinder using a peristaltic pump (type 314VBM, four rollers, max. 360rpm, Watson-Marlow Ltd., Zurich, Switzerland), which was computer-controlled and allowed flow rates of $75 \mathrm{~mL} / \mathrm{min}$. maximum. The pressure generated by increasing the liquid volume, using constant flow, was measured with a hydrostatic pressure sensor (digital manometer, LEX 1, -1 to 2 bar, accuracy within $0.05 \%$, Keller, Switzerland) positioned at the outlet of the cylinder. The deformation of the membrane was continuously monitored by video cameras (Point Grey, 1.4MP Color Grasshopper 1394b Camera, 2/3" CCD) mounted on the top and side of the cylinder.

\subsection{Stiffness comparison of fetal membranes and elastomeric membranes}

A total of 10 fetal membranes were collected with written consent at elective caesarean sections. Mean gestational age was $38 \pm 1$ weeks in the absence of labor, preterm rupture of membranes, chorioamnionitis, or chromosomal abnormalities. Fetal membranes and very high bonding elastomeric membranes (3M AG, Rüschlikon, Switzerland) of 0.5 and $1 \mathrm{~mm}$ in thickness were cut to a diameter of approximately $7 \mathrm{~cm}$. To obtain elastomeric membranes of $2 \mathrm{~mm}$ thickness, two $1 \mathrm{~mm}$ elastomeric membranes were bonded together by simply utilizing their inherent bonding capacity. The resulting $0.5,1.0$ and $2.0 \mathrm{~mm}$ thick elastomeric and the fetal membranes were immobilized on the cover ring and clamped onto the water-filled cylinder of our loading device. The loading experiment was performed by applying a constant flow rate of $12 \mathrm{~mL} / \mathrm{min}$ until the pressure reached 10,20 or $40 \mathrm{mbar}$. The height of the apex was evaluated by measurements from images taken with the side camera. 


\section{$1.4 \quad$ Elastomeric membrane gluing and mechanical testing}

Very high bonding elastomeric membranes of $0.5,1.0$ and $2.0 \mathrm{~mm}$ thickness were immobilized using the cover ring of the loading device. All elastomeric membranes were punched using a punch device (BP-30F, kai medical). $150 \mu \mathrm{L}$ of mussel glue was applied in a lubricated mold, resulting in a cylindrical plug with a thickness of $1.4 \mathrm{~mm}$ and diameter of $12.9 \mathrm{~mm}$. The traumatized and glued elastomeric membranes were then clamped onto the water-filled cylinder by tightening the screws using a dynamometric screwdriver at $0.2 \mathrm{Nm}$. Finally, the loading experiment was performed by applying a constant flow rate of $12 \mathrm{~mL} / \mathrm{min}$ until the elastomeric membranes ruptured. The membranes were continuously monitored optically and pressures were recorded.

\subsection{Evaluation and statistical analysis}

The critical burst pressure corresponds to the highest achieved pressure before rupture of the elastomeric membrane. Before the onset of inflation, diameters of the mussel glue plug $\left(\mathrm{P}_{0}\right)$ and the defect size $\left(\mathrm{D}_{0}\right)$ were measured and compared to the diameters of the plug $\left(\mathrm{P}_{1}\right)$ and the defect $\left(D_{1}\right)$ after stretching (referring to the critical state just prior to rupture). Data are shown throughout as [mean \pm SD]. Statistics were performed by the Kruskal Wallis und Mann Whitney test using the SPSS program (PASW statistics 18). 


\section{Results}

\subsection{Comparison of elastomeric membranes with fetal membranes}

To estimate the value of elastomeric membranes for the measurement of glue properties, the viscoelastic behaviors of $0.5,1$, and $2 \mathrm{~mm}$ elastomeric membranes were compared with fetal membranes (Figure 2). The deformation of the membranes during inflation (between 10mbar and 40mbar of pressure) was determined by measuring the elevation of the apex. The distension of the fetal membranes at $10 \mathrm{mbar}(3.3 \pm 0.3 \mathrm{~mm}$ height $)$ was very similar to that one of the $2 \mathrm{~mm}$ elastomeric membranes $(2.9 \pm 0.3 \mathrm{~mm})$. However, at pressures higher than $10 \mathrm{mbar}$, fetal membrane distension was only half as much as that one of the $2 \mathrm{~mm}$ elastomeric membranes.

\subsection{Standardization of puncture and sealing procedure}

In order to accurately determine the properties of the glue and the influence of the mechanical properties of the elastomeric membrane on plug stability, the formation of the membrane defects and the glue application were standardized (Figure 3A). Membranes with thicknesses of $0.5,1$ and $2 \mathrm{~mm}$ were punctured with a punch device to generate defined holes with diameters of $2.9 \pm 0.2 \mathrm{~mm}$ at the center of the membrane, which were efficiently and immediately glued to prevent defect propagation upon inflation. To control the extension and sealing geometry, lubricated molds were immobilized and centered on top of the membrane defect prior to the formation of a plug using $125 \mu \mathrm{L}$ of mussel glue. This approach led to the formation of a well-defined cylindrical plug with a diameter of $12.9 \pm 0.1 \mathrm{~mm}$ and thickness of $1.36 \pm 0.05 \mathrm{~mm}$. 


\subsection{Critical Pressure of traumatized and sealed elastomeric membranes}

Next, elastomeric membranes of different thickness $(0.5,1.0$ and $2.0 \mathrm{~mm})$ and different defined degrees of stiffness were tested using our biaxial inflation device after standardized defect formation and mussel glue application. A video presentation shows the inflation of a repaired $1 \mathrm{~mm}$ thick elastomeric membrane until rupture (Supplemental Movie 1). Typical examples of inflated elastomeric membranes just before rupture are also depicted (Figure 3A). The elastomeric membrane thickness, which translated to membrane stiffness, correlated with the size of the formed membrane bubble before rupture. Surprisingly, the critical pressure of mussel glue-sealed elastomeric membranes correlated with the stiffness of these membranes. By increasing the thickness of the elastomeric membranes from 0.5 to 1 and $2 \mathrm{~mm}$, the resistance to burst for all groups significantly improved from $12.6 \pm 1.6 \mathrm{mbar}$ to $22.4 \pm 1.7 \mathrm{mbar}$ and $45.1 \pm 5.5 \mathrm{mbar}$ respectively (Figure 3B). (Between the 0.5 and $2.0 \mathrm{~mm}$ group, $P \leq 0.01$; between all other groups, $P \leq 0.05)$.

\subsection{Distension of the mussel glue}

Based on the repair experiments above, we hypothesized that the performance of mussel glue is dependent on elastomeric membrane deformation. To determine the distension of the mussel glue in response to loading, the increase in diameter of the glue plug $(\mathrm{P})$ and the defect (D) were measured before inflation and immediately before the critical burst pressure was reached (Figure 4A). The diameters of the glue plug and the defect increased $49 \pm 34 \%$ and 94 $\pm 55 \%$, respectively, on the $2 \mathrm{~mm}$ thick elastomeric membranes (Figure $4 \mathrm{~B}$ ). The values were not significantly different between all the evaluated conditions. 


\section{Discussion}

This study presents data on the successful sealing of $3 \mathrm{~mm}$ elastomeric membrane defects using the mussel glue, a new promising tissue sealant that polymerizes in seconds and bonds even under wet conditions

In the last few years, several possible strategies to prevent or treat PROM have been described, including collagen plugs (Gratacos et al., 2000), native amniotic scaffolds (Mallik et al., 2007, Ochsenbein-Kolble et al., 2007), collagen plugs enriched with platelets and amniotic fluid cells (Liekens et al., 2008) in a rabbit model or gelatin sponge plugs in a ovine and primate model (Luks et al., 1999), fibrin glue (Sciscione et al., 2001, Harmanli et al., 1998), amniopatches (Quintero, 2001, Quintero et al., 1999, Quintero et al., 1996), amniografts (Quintero et al., 2002), maternal blood clot plugs (Sener et al., 1997), combinations of platelets, fibrin glue and powdered collagen slurry (Young et al., 2004), and gelatine sponges (Papanna et al., 2010) in humans. The relatively poor outcome using collagen-based matrices in conjunction with fibrin glue might be attributed to their high susceptibility to proteolytic remodelling and might be a result of instable plugging and leakage shortly after application (Quintero et al., 2002).

While plugging and healing of fetal membranes are attractive strategies for long-term sealing, we hypothesize that gluing of the membranes with biologically inert materials might be fully sufficient for temporary closure of the trauma site. In an in vivo experiment with diabetic mice, mussel glue was used to stick and engraft pancreatic islets on to the surface of the liver, leading to functional recovery for up to one year (Brubaker et al., 2010) Thus, the temporary presence of sodium periodate, which is readily reduced during chemical crosslinking (Burke et al., 2007), had no adverse effects in vitro and in vivo.

In order to measure the mechanical stability of mussel glue-repaired membranes, we used standardized conditions for membrane defect formation and mussel glue application. The use 
of elastomeric membranes with reproducible materials properties permitted the evaluation of the glue properties independent of the mechanically highly variable fetal tissue. Although these conditions are considerably different from possible in vivo treatment applications, defined plug geometries in combination with elastomeric membranes of defined viscoelastic properties provide valuable insight to gluing material properties.

Our data show that the critical burst pressure after the repair of $3 \mathrm{~mm}$ diameter puncture defects is strongly influenced by the mechanical properties of the membrane. Since our $2 \mathrm{~mm}$ thick elastomeric model membranes at a pressure of $40 \mathrm{mbar}$ almost reach the stiffness of fetal membranes, we think that the achieved mechanical stability of the repaired elastomeric membranes might be a good estimation of the expected performance of mussel glue on fetal membranes. Although, we have not performed measurements with more rigid substrates, the results indicate that stiffer fetal membranes might achieve even higher critical burst pressures than the $2 \mathrm{~mm}$ model membranes after repair with mussel glue.

The critical pressure measurements, along with the almost-identical dilatation seen in all instances immediately before burst, demonstrate that mussel glue in the current formulation and application geometry can be stretched to $94 \pm 54 \%$ in the defect and $49 \pm 34 \%$ in the plug area of the $2 \mathrm{~mm}$ thick elastomeric membrane before it ruptures. These findings indicate that the deformation behavior of the glued membrane is determined by the mechanical properties of the membrane, while rupture occurs when a critical state of deformation is reached in the glue plug. As a consequence, burst pressure level depends on the stiffness of the membrane and could be significantly higher than the $45.1 \pm 5.5 \mathrm{mbar}$ observed with the $2 \mathrm{~mm}$ thick elastomeric membrane. On the other hand, the present experiments indicate that the highly deformable mussel glue effectively seals the perforated elastomeric membrane, but does not offer a significant local reinforcement. This means that the glue plug will not protect the membrane from a possible increase in the size of the defect, but is sufficiently stable to resist 
the local loading generated by the pressure field. Recently, pre-sealing of the fetal membranes prior to fetoscopic surgery was tested in a model using the membrane of unfertilized chicken eggs (Carnaghan and Harrison, 2009). Although, some sealants in these experiments were effective in mitigating fluid leakage and enhancing resistance to shear forces and pressure, clinically-important properties of the materials have yet to be investigated.

The influence of the sealing shape, mussel glue thickness, and tension distribution are all subject to ongoing studies and are expected to leave potential for further optimization of gluing performance. This will be important regarding clinical applications, where the material will initially be engineered to seal right after invasive interventions such as amniocentesis or fetoscopy. Furthermore, it should be noted that the fetal membranes in vivo are reinforced by the surrounding myometrium such that stretch rather than pressure, might be the determining factor.

In conclusion, the data presented herein demonstrate that mussel glue, a new promising tissue sealant that bonds even under wet conditions, can be used to efficiently seal elastomeric membranes with viscoelastic properties comparable to those of fetal membranes. Further ex vivo and in in vivo evaluations are necessary and are already ongoing to confirm the applicability of mussel glue to fetal membrane repair. 


\section{Supplemental Informations}

Supplemental materials to this article can be found online.

\section{Acknowledgements}

We thank E. Kleiner and A. Kurmanaviciene for their competent technical support and V. Ramakrishnan for critically reviewing the manuscript. This work was supported by the Swiss National Fund (3200B-124925/1) and the European Cummunity's EuroStec Programm contract 037409 . This research was supported in part by National Institutes of Health grants

UL1 RR025741 and DE014193 to PBM

\section{Financial disclosure/competing interest:}

Dr. Messersmith holds equity in Nerites Corporation, a company that develops surgical sealants and adhesives.

\section{References}

BAR-COHEN, Y. 2004. Bionic Humans Using EAP as Artificial Muscles: Reality and Challenges. International Journal of Advanced Robotic Systems, 1: 217-222.

BILIC, G., BRUBAKER, C., MESSERSMITH, P. B., MALliK, A. S., QUINN, T. M., HALlER, C., DONE, E., GUCCIARDO, L., ZEISBERGER, S. M., ZIMMERMANN, R., DEPREST, J. \& ZISCH, A. H. 2010. Injectable candidate sealants for fetal membrane repair: bonding and toxicity in vitro. Am J Obstet Gynecol, 202, 85 e1-9.

BRUBAKER, C. E., KISSLER, H., WANG, L. J., KAUFMAN, D. B. \& MESSERSMITH, P. B. 2010. Biological performance of mussel-inspired adhesive in extrahepatic islet transplantation. Biomaterials, 31, 420-7. 
BURKE, S. A., RITTER-JONES, M., LEE, B. P. \& MESSERSMITH, P. B. 2007. Thermal gelation and tissue adhesion of biomimetic hydrogels. Biomed Mater, 2, 203-10.

CARNAGHAN, H. K. \& HARRISON, M. R. 2009. Presealing of the chorioamniotic membranes prior to fetoscopic surgery: preliminary study with unfertilized chicken egg models. Eur J Obstet Gynecol Reprod Biol, 144 Suppl 1, S142-5.

DEPREST, J. A., FlAKE, A. W., GRATACOS, E., VILlE, Y., HECHER, K., NICOLAIDES, K., JOHNSON, M. P., LUKS, F. I., ADZICK, N. S. \& HARRISON, M. R. 2010. The making of fetal surgery. Prenat Diagn, 30, 653-67.

DEVLIEGER, R., MILLAR, L. K., BRYANT-GREENWOOD, G., LEWI, L. \& DEPREST, J. A. 2006. Fetal membrane healing after spontaneous and iatrogenic membrane rupture: a review of current evidence. Am J Obstet Gynecol, 195, 1512-20.

EL KHWAD, M., STETZER, B., MOORE, R. M., KUMAR, D., MERCER, B., ARIKAT, S., REDLINE, R. W., MANSOUR, J. M. \& MOORE, J. J. 2005. Term human fetal membranes have a weak zone overlying the lower uterine pole and cervix before onset of labor. Biol Reprod, 72, 720-6.

GRATACOS, E., SANIN-BLAIR, J., LEWI, L., TORAN, N., VERBIST, G., CABERO, L. \& DEPREST, J. 2006. A histological study of fetoscopic membrane defects to document membrane healing. Placenta, 27, 452-6.

GRATACOS, E., WU, J., YESILDAGLAR, N., DEVLIEGER, R., PIJNENBORG, R. \& DEPREST, J. A. 2000. Successful sealing of fetoscopic access sites with collagen plugs in the rabbit model. Am J Obstet Gynecol, 182, 142-6.

HARMANLI, O. H., WAPNER, R. J. \& LONTZ, J. F. 1998. Efficacy of fibrin glue for in vitro sealing of human chorioamniotic membranes. J Reprod Med, 43, 986-90.

JANI, J. C., NiCOLAIDES, K. H., GRATACOS, E., VAlENCIA, C. M., DONE, E., MARTINEZ, J. M., GUCCIARDO, L., CRUZ, R. \& DEPREST, J. A. 2009. Severe 
diaphragmatic hernia treated by fetal endoscopic tracheal occlusion. Ultrasound Obstet Gynecol, 34, 304-10.

LEE, B. P., DALSIN, J. L. \& MESSERSMITH, P. B. 2002. Synthesis and gelation of DOPAmodified poly(ethylene glycol) hydrogels. Biomacromolecules, 3, 1038-47.

LEE, H., LEE, B. P. \& MESSERSMITH, P. B. 2007. A reversible wet/dry adhesive inspired by mussels and geckos. Nature, 448, 338-41.

LIEKENS, D., LEWI, L., JANI, J., HEYNS, L., POLIARD, E., VERBIST, G., OCHSENBEIN-KOLBLE, N., HOYLAERTS, M. \& DEPREST, J. 2008. Enrichment of collagen plugs with platelets and amniotic fluid cells increases cell proliferation in sealed iatrogenic membrane defects in the foetal rabbit model. Prenat Diagn, 28, 5037.

LUKS, F. I., DEPREST, J. A., PEERS, K. H., STEEGERS, E. A. \& VAN DER WILDT, B. 1999. Gelatin sponge plug to seal fetoscopy port sites: technique in ovine and primate models. Am J Obstet Gynecol, 181, 995-6.

MALLIK, A. S., FICHTER, M. A., RIEDER, S., BILIC, G., STERGIOULA, S., HENKE, J., SCHNEIDER, K. T., KURMANAVICIUS, J., BIEMER, E., ZIMMERMANN, R., ZISCH, A. H. \& PAPADOPULOS, N. A. 2007. Fetoscopic closure of punctured fetal membranes with acellular human amnion plugs in a rabbit model. Obstet Gynecol, $110,1121-9$

MESSERSMITH, P. B. 2008. Materials science. Multitasking in tissues and materials. Science, 319, 1767-8.

OCHSENBEIN-KOLBLE, N., JANI, J., LEWI, L., VERBIST, G., VERCRUYSSE, L., PORTMANN-LANZ, B., MARQUARDT, K., ZIMMERMANN, R. \& DEPREST, J. 2007. Enhancing sealing of fetal membrane defects using tissue engineered native amniotic scaffolds in the rabbit model. Am J Obstet Gynecol, 196, 263 e1-7. 
PAPANNA, R., MOLINA, S., MOISE, K. Y., MOISE, K. J., JR. \& JOHNSON, A. 2010. Chorioamnion plugging and the risk of preterm premature rupture of membranes after laser surgery in twin-twin transfusion syndrome. Ultrasound Obstet Gynecol, 35, 337 43.

QUINTERO, R. A. 2001. New horizons in the treatment of preterm premature rupture of membranes. Clin Perinatol, 28, 861-75.

QUINTERO, R. A., MORAlES, W. J., ALlEN, M., BORNICK, P. W., ARROYO, J. \& LEPARC, G. 1999. Treatment of iatrogenic previable premature rupture of membranes with intra-amniotic injection of platelets and cryoprecipitate (amniopatch): preliminary experience. Am J Obstet Gynecol, 181, 744-9.

QUINTERO, R. A., MORALES, W. J., BORNICK, P. W., ALLEN, M. \& GARABELIS, N. 2002. Surgical treatment of spontaneous rupture of membranes: the amniograft--first experience. Am J Obstet Gynecol, 186, 155-7.

QUINTERO, R. A., ROMERO, R., DZIECZKOWSKI, J., MAMMEN, E. \& EVANS, M. I. 1996. Sealing of ruptured amniotic membranes with intra-amniotic plateletcryoprecipitate plug. Lancet, 347, 1117.

SCISCIONE, A. C., MANLEY, J. S., POLlOCK, M., MAAS, B., SHLOSSMAN, P. A., MULLA, W., LANKIEWICZ, M. \& COLMORGEN, G. H. 2001. Intracervical fibrin sealants: a potential treatment for early preterm premature rupture of the membranes. Am J Obstet Gynecol, 184, 368-73.

SENAT, M. V., DEPREST, J., BOULVAIN, M., PAUPE, A., WINER, N. \& VILlE, Y. 2004. Endoscopic laser surgery versus serial amnioreduction for severe twin-to-twin transfusion syndrome. $N$ Engl J Med, 351, 136-44.

SENER, T., OZALP, S., HASSA, H., YALCIN, O. T. \& POLAY, S. 1997. Maternal blood clot patch therapy: a model for postamniocentesis amniorrhea. Am J Obstet Gynecol, $177,1535-6$. 
WAITE, J. H. 1999. Reverse engineering of bioadhesion in marine mussels. Ann N Y Acad Sci, 875, 301-9.

WAITE, J. H. \& TANZER, M. L. 1980. The bioadhesive of Mytilus byssus: a protein containing L-dopa. Biochem Biophys Res Commun, 96, 1554-61.

YAMADA, K., CHEN, T., KUMAR, G., VESNOVSKY, O., TOPOLESKI, L. D. \& PAYNE, G. F. 2000. Chitosan based water-resistant adhesive. Analogy to mussel glue. Biomacromolecules, 1, 252-8.

YOUNG, B. K., ROMAN, A. S., MACKENZIE, A. P., STEPHENSON, C. D., MINIOR, V., REBARBER, A. \& TIMOR-TRITSCH, I. 2004. The closure of iatrogenic membrane defects after amniocentesis and endoscopic intrauterine procedures. Fetal Diagn Ther, 19, 296-300. 


\section{Figure Legends}

FIGURE 1: Biaxial stretching device. (A) The setup consists of a water-filled cylinder where membranes are mounted and inflated with a peristaltic pump. During the inflation, continuous monitoring by a pressure sensor and CCD-cameras is performed. (B) Example of an inflated elastomeric membrane.

FIGURE 2: Deformation behavior of fetal and elastomeric membranes. The distension of elastomeric membranes of $0.5,1.0$ and $2.0 \mathrm{~mm}$ thickness $(\mathrm{n}=5)$ and fetal membranes $(\mathrm{n}=10)$ was compared at pressures ranging up to $40 \mathrm{mbar}$ by determination of the elevation of the apex. (mean $\pm \mathrm{SD})$

FIGURE 3 Biaxial stretching of repaired elastomeric membranes under standardized conditions. (A) Elastomeric membranes of $0.5,1.0$ and $2.0 \mathrm{~mm}$ thickness were punched to form $3 \mathrm{~mm}$ defect, which was sealed by a disc shaped (12.9mm diameter, $1.4 \mathrm{~mm}$ thickness) mussel glue plug. Typical images of inflated elastomeric membranes immediately before rupture, corresponding critical pressures are shown. (B) By increasing the thickness of the elastomeric membranes, the achieved critical pressure increased significantly. The tested groups are all significant in between each other (mean $\pm \mathrm{SD}, * P \leq 0.05, * * P \leq 0.01$ ).

FIGURE 4: Distension of the mussel glue. (A) Typical images of repaired elastomeric membranes with different thickness are depicted before inflation and at critical pressure. The defect size $D$ and the mussel glue plug size $P$ are indicated. (B) The distension of the defects and the mussel glue plugs, as calculated in percentage of the corresponding initial diameter, were not significantly different between elastomeric membranes with different thicknesses $($ mean $\pm \mathrm{SD})$. 


\section{Figure 1a}

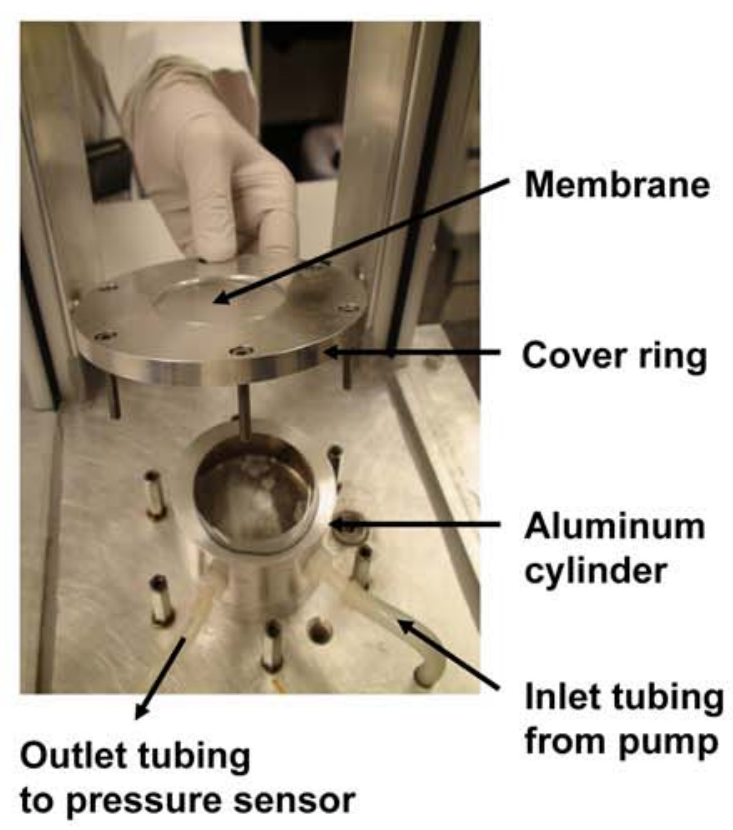

\section{Figure 1b}

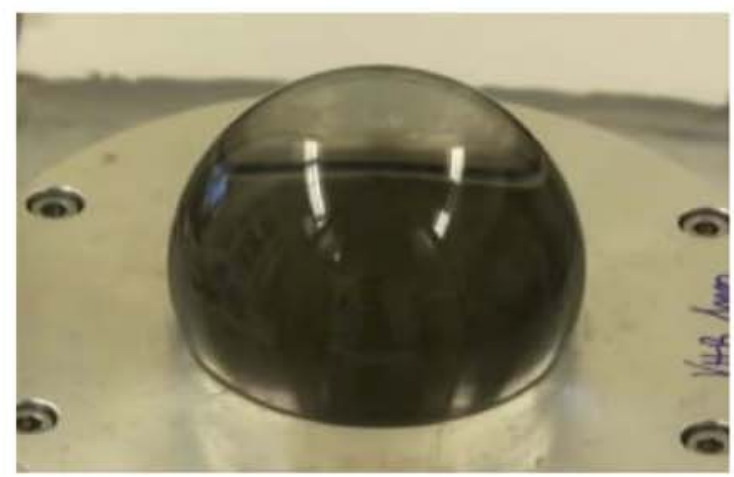




\section{Figure 2}
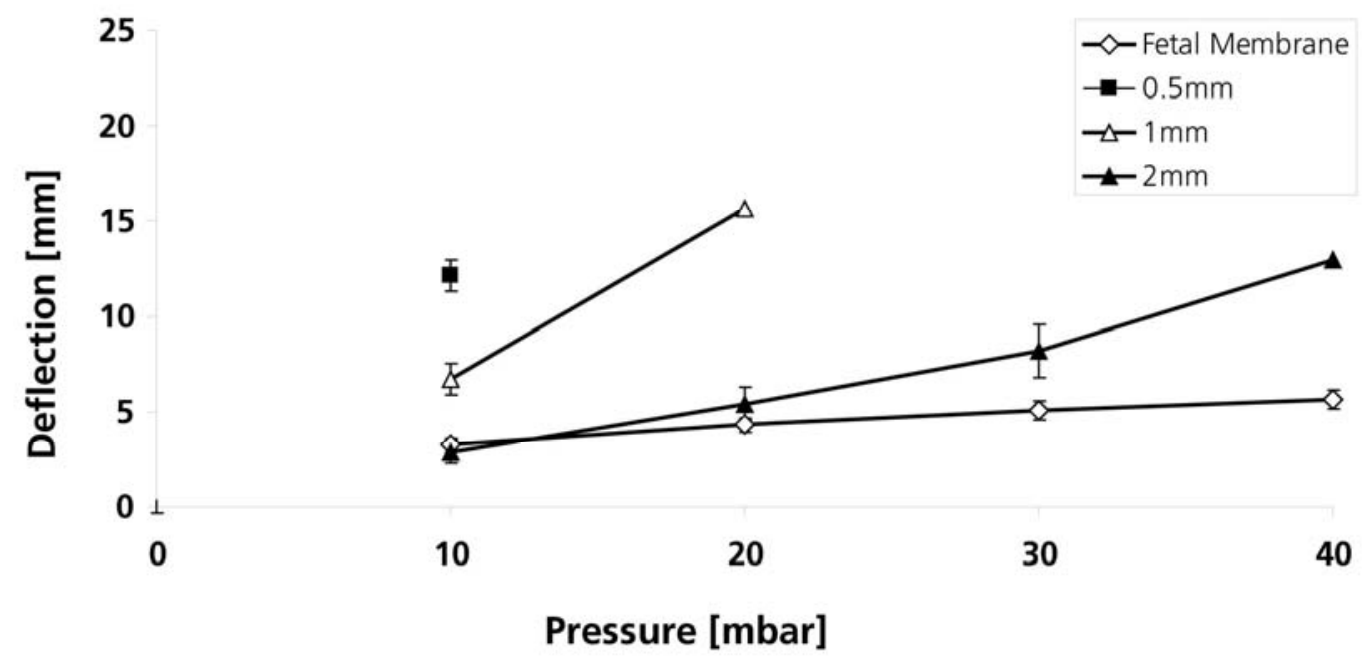


\section{Figure 3}

A

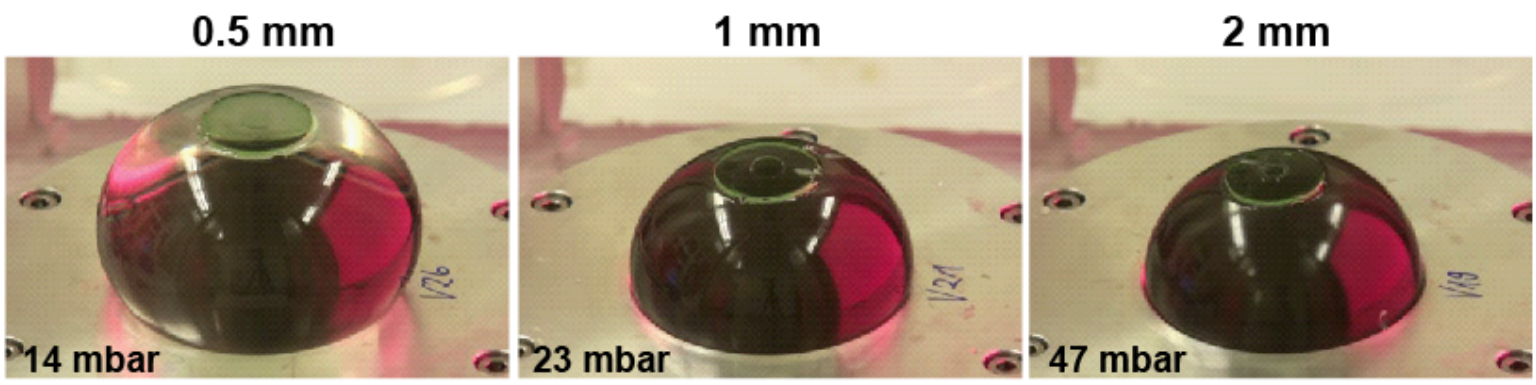

B

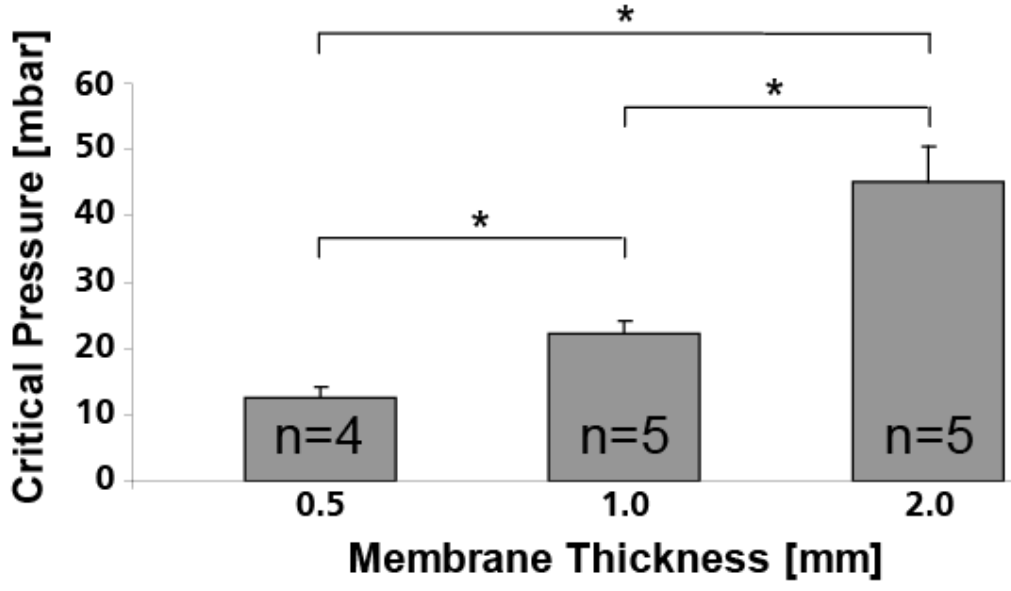




\section{Figure 4}

A
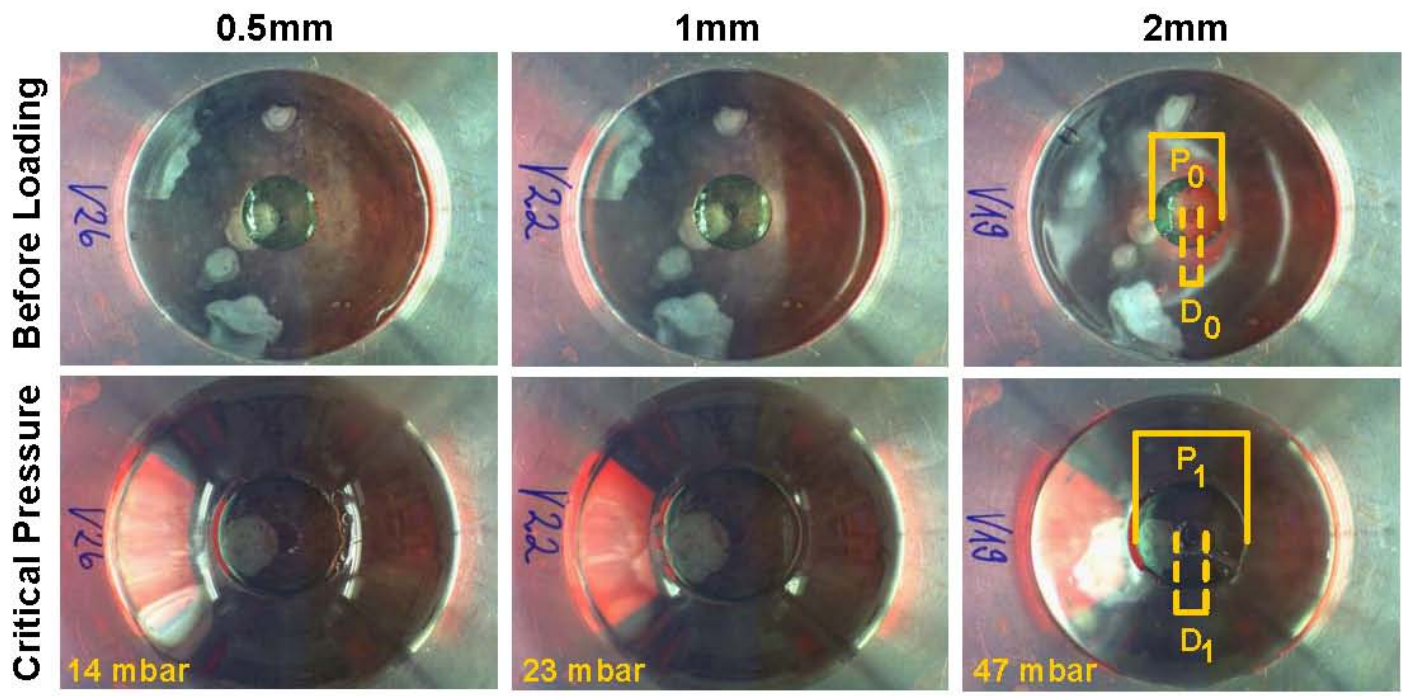

B

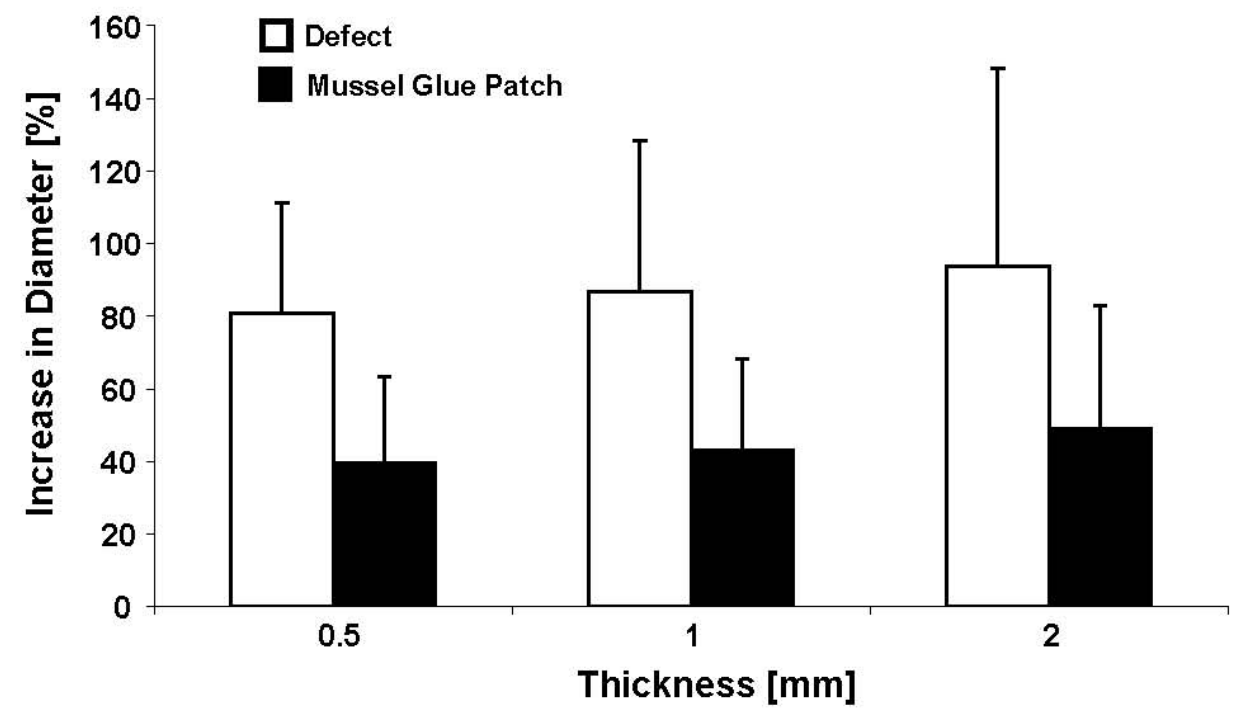

